\title{
Association among quantitative, chromosomal and enzymatic traits in a natural population of Drosophila melanogaster
}

\author{
M Hernández, JM Larruga, AM González, VM Cabrera \\ University of La Laguna, Department of Genetics, \\ Canary Islands, Spain
}

(Received 27 March 1992; accepted 9 February 1993)

\begin{abstract}
Summary - A sample of 1359 males and 1259 females from a natural population of Drosophila melanogaster of the Canary Islands was simultaneously examined for wing length, inversion polymorphisms, and gene variation at 10 allozyme loci. Correlations and nonrandom associations between those genetic traits were estimated. In contrast to previous studies, large amounts of linkage disequilibrium have been found. Frequencies of significant gametic associations between linked and unlinked elements were $100 \%$ and $25 \%$, respectively, for chromosome inversions, $81 \%$ and $4 \%$ for chromosome inversions, and allozymes, and $36 \%$ and $0 \%$ for pairs of allozymes. Temporal stability in chromosome and allozyme frequencies and the average number of alleles per locus rule out a recent bottleneck effect. Mean and coefficient of variation of wing length are correlated with the degree of heterokaryotypy (both negatively) and with the degree of heterozygosis (positively for the mean, negatively for the coefficient of variation), mainly implying chromosome 3 elements. Individuals with wing length above (or below) a standard deviation from the population mean showed characteristics for the other genetic traits which resembled those of northern (or southern) populations of the species.
\end{abstract}

Drosophila melanogaster / wing size / chromosomal inversion / enzyme / linkage disequilibrium

Résumé - Associations entre un caractère quantitatif et des caractères chromosomiques et enzymatiques dans une population naturelle de Drosophila melanogaster. Un échantillon de 1359 mâles et 1259 femelles d'une population naturelle de Drosophila melanogaster des îles Canaries a été étudiée pour la longueur de l'aile, le polymorphisme des inversions et les variations géniques à 10 locus d'allozymes. Les corrélations et les

Correspondence and reprints: M Hernández Ferrer, Departemento de Genética, Facultad de Biologia, Universidad de La Laguna, La Laguna, Tenerife 38271, Spain. 
associations non aléatoires entre les caractères génétiques ont été estimées. Contrairement à des études précédentes, d'importants déséquilibres de liaison ont été trouvés. Les fréquences des associations gamétiques significatives entre éléments portés par le même chromosome ou par des chromosomes différents sont de $100 \%$ et $25 \%$ respectivement pour les inversions chromosomiques, $81 \%$ et $4 \%$ pour les inversions et les allozymes, et $36 \%$ et $0 \%$ pour les couples d'allozymes. La stabilité dans le temps des fréquences chromosomiques et allozymiques permet d'écarter un effet récent de réduction d'effectif. La moyenne et le coefficient de variation de la longueur d'aile sont en corrélation avec le degré d'hétérocaryotypie (corrélations négatives pour les 2) et avec le degré d'hétérozygotie (corrélation positive pour la moyenne, négative pour le coefficient de variation), impliquant principalement des éléments du chromosome 3. Les individus avec une longueur d'aile supérieure (ou inférieure) d'un écart type à la moyenne de la population montrent, pour les autres caractères génétiques, des caractéristiques qui les rapprochent des populations naturelles nordiques (ou méridionales) de l'espèce.

Drosophila melanogaster/ taille de l'aile / inversion chromosomique / enzyme / déséquilibre gamétique

\section{INTRODUCTION}

Selection effects in higher organisms are obvious at morphological, physiological and chromosomal levels but harder to detect at the molecular level (Lewontin, 1974; Nei, 1975; Kimura, 1983). Theories to connect phenotypes with their genotypic bases differ in the relative strength given to independence or epistasis among the different sets of genes that determine phenotypic traits (Crow, 1987). Experimental approaches have mainly consisted of the study of correlated response at different levels of variation, driven by artificial selection on a presumably adaptive trait, but the validity of the results of artificial selection to explain natural selection is controversial (Nei, 1971).

An area of population genetics where changes of variation at different levels have been detected is in studies on the geographical structure of natural populations. In the species Drosophila melanogaster, the existence of latitudinal clines has been demonstrated for morphological and physiological characters (Tantawy and Mallah, 1961 ; David and Bocquet, 1975; David et al, 1977; Stalker, 1980; Cohan and Graf, 1985; Watada et al, 1986; Coyne and Beecham, 1987), additive genetic variance of viability (Kusakabe and Mukai, 1984), chromosome inversion polymorphism (Mettler et al, 1977; Inoue and Watanabe, 1979; Stalker, 1980; Knibb et al, 1981), and allozyme frequencies (Schaffer and Johnson, 1974; Voelker et al, 1978; Singh et $a l, 1982$; Anderson and Oakeshott, 1984; Inoue et al, 1984; Singh and Rhomberg, 1987). Nevertheless, a clear connection among morphological, chromosomal and enzymatic clines has not yet been well established (Voelker et al, 1978; Stalker, 1980; Knibb, 1983; Kusakabe and Mukai, 1984). This is explainable if it is assumed that natural selection is acting simultaneously upon several morphological and physiological traits that are largely genetically independent (David et al, 1977), and if different gene combinations can give the same phenotypic result under selection. On the contrary, if selection is mainly acting on a morphological or physiological 
character highly dependent on a specific genetic combination, association among different genetic levels should be detectable if sufficient sample sizes have been employed (Brown, 1975; Zapata and Alvarez, 1987). To test the validity of this supposition, we have characterized the variability in a natural population of $D$ melanogaster, sampled in the most favorable season, for wing length as a measure of body size, chromosomal inversion polymorphism, and 10 enzymatic loci. In order to detect relevant associations among traits that could have been overlooked in the past, the sample was an order of magnitude larger than in preceding estimates.

From a selective point of view, both clines and seasonal changes can be considered as the effect of short limited directional selection of several highly correlated environmental features on the phenotypic variance of the populations. In Drosophila, their more visible effect is a change in mean and variance of body size. Nevertheless, possible associations of this trait with others can be explained as well by selection as by historical factors. In an attempt to distinguish between these hypotheses, the total sample was subdivided into subsamples with mean sizes similar to those of temperate and tropical natural populations, reanalyzed for the other studied traits and their possible interactions, and then compared with any outstanding features of natural southern and northern populations of the species for these same characters.

\section{MATERIALS AND METHODS}

A sample of 1359 males and 1259 females of Drosophila melanogaster was collected, using crushed grape skin traps, in an orchard in the locality of Guimar, Tenerife (Canary Islands) during the vintage period, in September 1984, and the following analyses were conducted.

\section{Morphological analysis}

The right wing, whenever possible, or the left wing of each fly was dissected and mounted on a slide. The wing length was measured as the linear distance between the intersection of the 3rd longitudinal vein with the wing tip and the anterior crossvein. This measurement is known to be genetically and phenotypically correlated with other measurements of body size in $D$ melanogaster (Reeve and Robertson, 1953; David et al, 1977).

\section{Cytological analysis}

For karyotype determination, wild males were crossed individually with virgin females of the Oregon strain, which is homokaryotypic for the standard (st) arrangement of all chromosomal arms in this species. Wild females were first frozen at $-11 \pm 1^{\circ} \mathrm{C}$ for $20 \mathrm{~min}$ in order to delay the sperm of wild males, and then transferred to fresh medium every day to eliminate the fertilized eggs (Mayer and Baker, 1983). After this, females were crossed with males of the Oregon strain. In both cases 7 third-instar larvae from $F_{1}$ were dissected and the salivary gland chromosomes observed.

We have followed the cytological nomenclature described in Lindsley and Grell (1967), using the photographic maps of Lefevre (1976) to identify the inversion breakpoints. 


\section{Enzymatic analysis}

After crosses yielded offspring, wild flies were electrophoresed in horizontal starchgels and the following enzyme loci analyzed: 6-phosphogluconate dehydrogenase (6-Pgdh, map position $1-0.6$ ), glucose-6-phosphate dehydrogenase (G-6-pdh, map position $1-63.0)$. $\alpha$-Glycerophosphate dehydrogenase $(\alpha-G p d h$, map position $2-17.8)$, alcohol dehydrogenase ( $A d h$, map position $2-50.1)$, hexokinase-C ( $H k-C$, map position 2-73.5), phosphoglucomutase ( $P g m$, map position 3-43.4), esteraseC (Est-C, map position $3-47.7)$ and octanol dehydrogenase (Odh, map position 3-49.2). In addition, another 2 enzyme loci, esterase-6 (Est-6, map position 3-36.8) and glucose dehydrogenase (Gld, map position 3-48.5), were assayed only in males. Gel preparation, electrophoretic, and enzyme staining methods were as described by González et al (1982), except for Gld which was stained as in Cavener (1980).

\section{Statistical analysis}

Linkage disequilibria were estimated from zygotic frequencies following Cockerham and Weir (1977) and Weir and Cockerham (1979) methods, and the normalized average correlation, $R$, of Langley et al (1978). Only the 2 more frequent alleles or rearrangements were used, pooling the rarest with the more common ones (Weir and Cockerham, 1978). The unique exception was the $3 R$ arm, in which the $s t$ and $I n$ (3R) $P$ arrangements were compared. For pairs of loci involving a sex-linked locus, only female genotypic frequencies were used. We considered as coupling gametes those with the 2 most or the 2 least frequent alleles and/or arrangements, as in Langley et al (1974).

In order to study the possible associations among qualitative and quantitative traits, several statistical analyses were carried out. Differences in mean wing length among the different genotypic classes involving the 2 more frequent alleles for each enzymatic locus and the 2 common cosmopolitan rearrangements for each chromosome arm were tested by an analysis of variance (ANOVA) plus regression, using the breakdown and means subprograms from SPSS (Nie et al, 1975). The contribution of each factor to the genetic variance of the quantitative trait was estimated according to Boerwinkle and Sing (1986) and the partition of this contribution into additive and dominance components following the method described by Ruiz et al (1991). The overall degree of heterokaryotypy and heterozygosis per individual was, respectively, established as the number of chromosome arms or enzymatic loci studied in the heterozygous state. Then the relationships between individual heterokaryotypy or heterozygosis and wing length among the total male and female samples were determined by Pearson's product-moment correlation $(r)$. Individuals with the same degree of heterokaryotypy and heterozygosis were pooled in classes, and correlation between these classes and their means in wing length was calculated by Kendall's coefficient of rank correlation (Sokal and Rohlf, 1981).

In addition, 2 analyses were conducted to assess associations of variance in wing length with heterozygosity at the chromosomal and gene level. For each locus and chromosome arm, the differences between the coefficients of variation for the morphological character in homozygous and heterozygous groups were calculated, and the Wilcoxon's signed-ranks test (Sokal and Rohlf, 1981) followed to analyze the relationship between heterozygosity and variation of the quantitative 
trait. Correlations between heterokaryotypic and heterozygotic classes and their respective coefficients of variation in wing length were also calculated by Kendall's coefficient of rank correlation (Sokal and Rohlf, 1981).

The total sample was subdivided into 3 classes: at least 1 standard deviation above the mean (Class I), within 1 standard deviation from the mean (Class II) and at least 1 standard deviation below the mean (Class III), in order that the upper and lower classes would have a mean wing size respectively similar to the northern and southern natural populations. The same kind of association analysis as in the total sample was carried out on them.

\section{RESULTS}

As no significant differences were found in inversion or in allozymic frequencies between sexes, data of male and female have been pooled whenever possible.

\section{Quantitative variation}

Wing length means were $1.539 \pm 0.003 \mathrm{~mm}$ for males and $1.710 \pm 0.004 \mathrm{~mm}$ for females. The same values for Classes I, II and III were: $1.679 \pm 0.003,1.545 \pm 0.002$ and $1.390 \pm 0.003$ in males and $1.869 \pm 0.003,1.720 \pm 0.002$ and $1.531 \pm 0.004$ in females respectively.

\section{Karyotype variation}

In the present study (table I) a sample of $>2500 X$ chromosomes and 3700 autosomes from the natural population of Guimar was examined. A total of 38 inversions, all of them paracentric, was found compared with only 16 detected in a previous survey in the same locality where only 226 chromosomes were analyzed (Afonso et al, 1985). Following the nomenclature of Mettler et al (1977), we have distinguished the following inversions: 4 common cosmopolitan; 3 rare cosmopolitan; 4 endemic recurrent previously detected in this same population (Afonso et al, 1985); and 27 new endemic rare inversions. Three of these new inversions were found on chromosome $X$ which is usually monomorphic in wild populations of $D$ melanogaster (Ashburner and Lemeunier, 1976) although Stalker (1976) also found $X$ polymorphism in American samples.

Overlapping inversions are very scarce in this species (Stalker, 1976; Zacharopoulos and Pelecanos, 1980). In this study only 1 such complex rearrangement was found, that being the common cosmopolitan In ( $3 L) P$ and the endemic In (3L) $64 C$; $69 \mathrm{~F}$ occurring in the same chromosome. Another overlapping inversion had previously been found in this same locality but affecting the $2 L$ arm (Afonso et al, 1985). In an inversion distribution, $8(21 \%)$ were found on $2 L, 6(16 \%)$ on $2 R$, $7(18 \%)$ on $3 L, 14(37 \%)$ on $3 R$ arms and $3(8 \%)$ on chromosome $X$. The inversion frequency per individual in the total sample was 1.15 ; it decreased to 1.01 in Class I and increased to 1.23 in Class III. Individuals were sorted in groups according to their number of inversions; 6 classes with none to 5 inversions per individual were formed. When this observed distribution was compared with that expected under random association among inversions according to their relative frequencies, 
Table I. Inversion frequencies and observed and expected heterozygosities in the total sample.

\begin{tabular}{lcccccccc}
\hline Arm & Sample & st & In $^{\mathrm{a}}$ & $\mathrm{C}$ & Mo & Others $^{\mathrm{b}}$ & Obs het & Exp het \\
\hline $2 L$ & 3722 & 0.7633 & 0.2337 & - & - & 0.0030 & $0.379 \pm 0.011$ & $0.363 \pm 0.007$ \\
$2 R$ & 3706 & 0.9139 & 0.0842 & - & - & 0.0019 & $0.157 \pm 0.009$ & $0.158 \pm 0.008$ \\
$3 L$ & 3704 & 0.8898 & 0.1007 & - & - & 0.0095 & $0.200 \pm 0.009$ & $0.198 \pm 0.008$ \\
$3 R$ & 3694 & 0.8473 & 0.0652 & 0.0782 & 0.0038 & 0.0055 & $0.272 \pm 0.010$ & $0.272 \pm 0.009$ \\
$X$ & 2536 & 0.9988 & - & - & - & 0.0012 & $0.001 \pm 0.001$ & $0.002 \pm 0.001$ \\
Mean & & & & & & & $0.252 \pm 0.008$ & $0.248 \pm 0.007$ \\
\hline
\end{tabular}

a In corresponds to $\operatorname{In}(2 L) t$, In $(2 R) N S$, In $(3 L) P$ or $\operatorname{In}(3 R) P$; ${ }^{\mathrm{b}}$ others gather the rare cosmopolitan $(\operatorname{In}(3 L) 66 D E ; 71 A B)$, the endemic recurrent $(\operatorname{In}(2 L) 22 A B ; 26 C D)$, $\operatorname{In}(2 R) 42 C ; 50 A, \operatorname{In}(2 R) 51 B ; 56 F-57 A, \operatorname{In}(3 R) 88 C D ; 92 A$ and $\operatorname{In}(3 R) 94 A B ; 97 F-98 A)$ and the endemic rare (In(2L) 21CD;25DE, In(2L)22AB;26BC, In(2L)22C;25F-26A, $\operatorname{In}(2 L) 23 E ; 30 B, \operatorname{In}(2 L) 26 D ; 30 E F, \operatorname{In}(2 L) 30 E F ; 36 E F, \operatorname{In}(2 R) 43 B C ; 53 C, \operatorname{In}(2 R) 45 A B$; $54 D E, \quad \operatorname{In}(2 R) 56 D ; 60 E, \quad \operatorname{In}(3 L) 64 C ; 72 C, \quad \operatorname{In}(3 L) 65 A ; 70 C, \quad \operatorname{In}(3 L) 65 E F ; 78 D E$, $\operatorname{In}(3 L) 67 B ; 76 D, \operatorname{In}(3 L) P+64 C ; 69 F, \operatorname{In}(3 R) 83 B C ; 86 D E, \operatorname{In}(3 R) 84 E F ; 97 A, \operatorname{In}(3 R) 85 D$; 87EF, In(3R)85EF;94A, In(3R) $86 F ; 97 A, \quad \operatorname{In}(3 R) 87 E F ; 92 A, \quad \operatorname{In}(3 R) 87 E F ; 94 A$, $\operatorname{In}(3 R) 92 D ; 98 F, \operatorname{In}(3 R) 93 E, 98 E F, \operatorname{In}(X) 6 D ; 15 C, \operatorname{In}(X) 11 A ; 14 D$ and $\operatorname{In}(X) 12 F ; 19 A D)$ inversions.

a significant excess of individuals without or with 3 or more inversions and a corresponding deficit of those with only one was observed $\left(\chi^{2}=23.06,5 \mathrm{df}, p<0.001\right)$. This was just what Knibb et al (1981) reported for populations latitudinally far from the equator, with fewer than one inversion per individual.

When comparing the cosmopolitan inversion frequencies with those found in the same season of the previous year (Afonso et al, 1985), only those on the $3 R$ arm showed heterogeneity $\left(\chi^{2}=12.85,3 \mathrm{df}, p<0.01\right)$. Frequency of the $s t$ arrangement increased in $1984(0.847)$ compared to $1983(0.758)$ at the expense of a decrease in the common $\operatorname{In}(3 R) P$ and the rare $\operatorname{In}(3 R) C$ cosmopolitan inversions.

The more relevant effects of partition for wing length on chromosomal polymorphism were an increase in mean heterokaryotypy $(0.282 \pm 0.026)$ and in inversion frequency per individual (1.23) for small flies (Class III) and a decrease $(0.216 \pm 0.022)$ and (1.01) respectively for the larger ones (Class I). In a more detailed chromosome by chromosome analysis, significant differences were detected between Classes I and III for inversion frequencies of $2 L$ and $3 R$ arms, In(2L)t $\left(\chi^{2}=5.36,1 \mathrm{df}, p<0.05\right)$ and $\operatorname{In}(3 R) P\left(\chi^{2}=5.16,1 \mathrm{df}, p<0.05\right)$ having lower frequencies in Class I than in Class III. Furthermore, Class I shows the only observed Hardy - Weinberg $(\mathrm{HW})$ deviation $\left(\chi^{2}=5.23,1 \mathrm{df}, p<0.05\right)$ due to a deficit of homokaryotypes $t / t$. Thus, long wing flies have higher frequencies of standard $(s t)$ rearrangements and lower inversion heterozygosities than those with short wings, which is in agreement with the morphological (Tantawy and Mallah, 1961; David et al, 1977; Watada et al, 1986; Coyne and Beechan, 1987) and chromosomal (Mettler et al, 1977; Knibb, 1982) latitudinal clines found in this species. 


\section{Isozyme variation}

Table II gives allelic frequencies, and observed and expected frequencies of heterozygotes for the 10 enzymatic loci studied. Loci with significant departures from HW equilibrum were $\alpha-G p d h, H k-C, E s t-6$ and Est-C. In all of them significance was due to an excess of homozygotes, the overall mean heterozygosity observed $(0.231$ $\pm 0.009)$ being slightly less than the expected value $(0.243 \pm 0.006)$. The average number of alleles per locus for the total sample was 4.3 , nearly twice as large as the value found (2.3) in previous screenings of the same locality (Cabrera et al, 1982; Afonso et al, 1985). This difference is attributable to differences in sample size, which is 20 times greater in this study. When only rare alleles with frequencies high enough to be detectable with former sample sizes were considered, the average number of alleles per locus (2.5) was similar along years, and did not differ from that calculated for the total species (2.8) using the same set of loci taken from the data of Choudhary and Singh (1987), who studied 15 worldwide populations.

When we compare the common allozyme frequencies found in this study with those of a previous sample of the same locality (Afonso et al, 1985), only one comparison involving the sex-linked locus 6 -Pgdh was significantly heterogeneous $\left(\chi^{2}=13.72,1 \mathrm{df}, p<0.001\right)$.

Contrary to its effect on chromosomal variation, the population subdivision according to wing length did not affect the enzymatic mean heterozygosity which was similar in all 3 Classes $(0.227 \pm 0.023,0.234 \pm 0.012$ and $0.222 \pm 0.022$ for Class I, II and III respectively). Nevertheless, in a locus by locus comparison there are significant differences between Classes for $\operatorname{Adh}\left(\chi^{2}=4.04,1 \mathrm{df}, p<0.05\right)$ and Est-C $\left(\chi^{2}=4.08,1 \mathrm{df}, p<0.05\right)$, with $A d h^{100}$ and Est- $C^{101}$ (alleles 100 and 101 for $A d h$ and Est-C loci, respectively) increasing in Class I when compared to Class III. It is worth mentioning that these same loci showed clinal variation in $D$ melanogaster with both alleles having higher frequencies in temperate than in tropical populations (Singh and Rhomberg, 1987). A new departure from HW equilibrium was observed in Class I for the $\operatorname{Adh}$ locus $\left(\chi^{2}=6.8,1 \mathrm{df}, p<0.01\right)$ due to a deficit in observed $95 / 95$ homozygotes, which parallels the decrease, already mentioned, of $t / t$ homokaryotypes in the same Class.

\section{Associations between wing length and karyotype}

When ANOVAs were carried out no heterogeneity was found for $2 L$ and $2 R$ arms in any sex. However, significant associations were observed for both chromosome 3 arms in males, st/st homokaryotypes having on average wings significantly larger than individuals carrying $P$ inversions (tables III, IV). Although $F$ values were not significant, a similar trend was observed for females (table III). Stalker (1980) found significantly lower wing-loading indices (larger wings relative to thorax volume) in wild flies homozygous for $s t$ rearrangements in $2 R$ and/or $3 R$ arms when compared to flies carrying inversions in these arms. He reached the conclusion that wild flies with high frequencies of $s t$ chromosomes are karyotypically northern, and selectively favored during the cold season.

A slight but significant negative product-moment correlation was observed between individual wing length and individual heterokaryotypy, both in males 


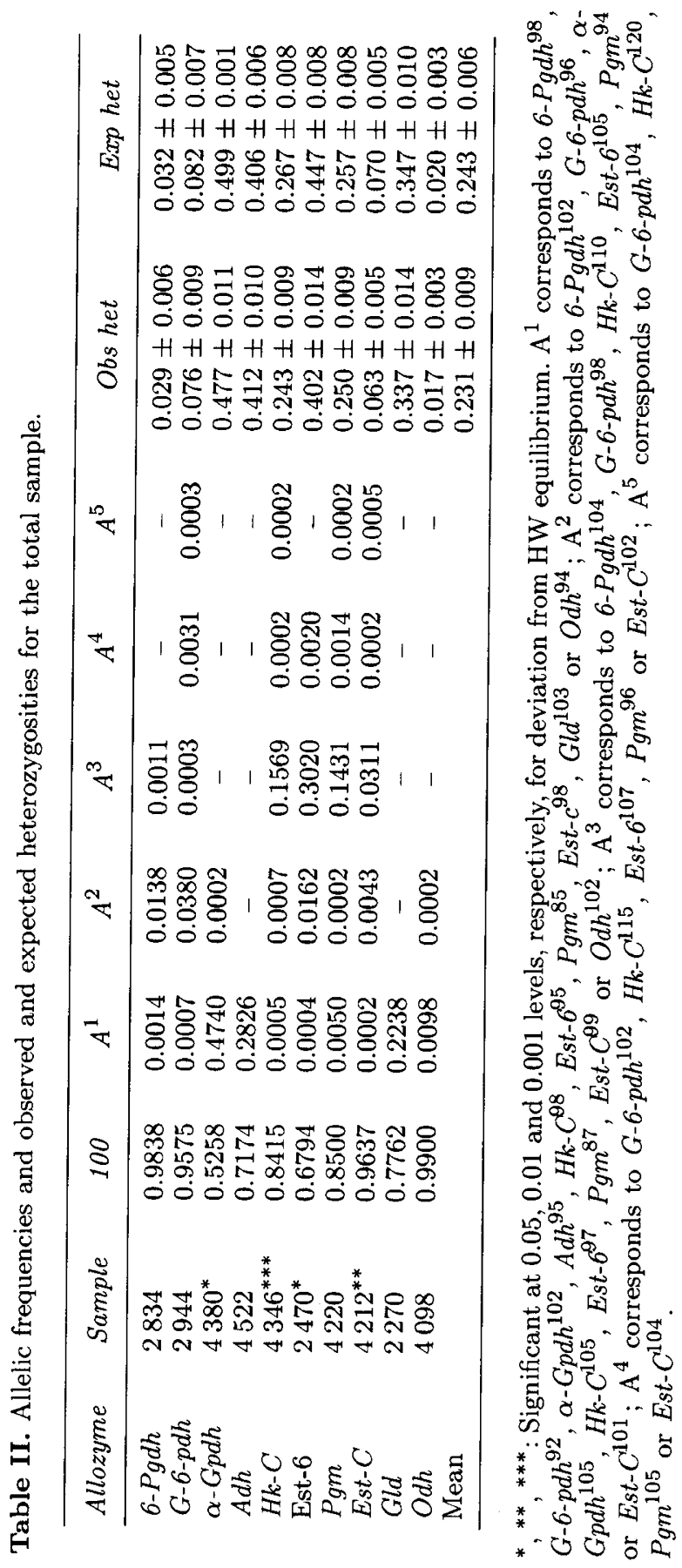


Table III. Mean wing size in $\mathrm{mm}(\bar{Y})$, standard deviation (SD) and sample size $(N)$ for the 3 karyotypes involving the 2 more common arrangements for both arms of third chromosome.

\begin{tabular}{|c|c|c|c|c|c|c|}
\hline Arm & Sex & & st/st & st/P & $\mathrm{P} / \mathrm{P}$ & Total \\
\hline \multirow[t]{6}{*}{$3 L$} & \multirow[t]{3}{*}{ Males } & $\bar{Y}$ & 1.5412 & 1.5207 & 1.5505 & 1.5377 \\
\hline & & SD & 0.0968 & 0.0868 & 0.0612 & 0.0952 \\
\hline & & $N$ & 829 & 178 & 8 & 1015 \\
\hline & \multirow[t]{3}{*}{ Females } & $\bar{Y}$ & 1.7130 & 1.7106 & 1.8010 & 1.7116 \\
\hline & & SD & 0.1116 & 0.1032 & 0.0607 & 0.1095 \\
\hline & & $N$ & 471 & 149 & 3 & 623 \\
\hline \multirow[t]{6}{*}{$3 R$} & \multirow[t]{3}{*}{ Males } & $\bar{Y}$ & 1.5417 & 1.5184 & 1.5576 & 1.5387 \\
\hline & & SD & 0.0948 & 0.0948 & 0.1070 & 0.0951 \\
\hline & & $N$ & 875 & 130 & 3 & 1008 \\
\hline & \multirow[t]{3}{*}{ Females } & $\bar{Y}$ & 1.7128 & 1.6929 & 1.5880 & 1.7101 \\
\hline & & SD & 0.1099 & 0.1132 & - & 0.1105 \\
\hline & & $N$ & 547 & 80 & 1 & 628 \\
\hline
\end{tabular}

Table IV. Results of the 1-way ANOVA performed to test for wing length differences (in $\mathrm{mm} \times 10^{2}$ ) among karyotypes of $3 L$ and $3 R$ chromosomal arms in males.

\begin{tabular}{|c|c|c|c|c|c|c|}
\hline \multirow[t]{2}{*}{ Source of variation } & \multicolumn{3}{|c|}{$3 \mathrm{~L}$} & \multicolumn{3}{|c|}{$3 \mathrm{R}$} \\
\hline & $d f$ & $M S$ & $\mathrm{~F}$ & $d f$ & $M S$ & $\mathrm{~F}$ \\
\hline Among karyotypes & 2 & 311.766 & $3.46^{*}$ & 2 & 313.039 & $3.48^{*}$ \\
\hline Regression & 1 & 454.603 & $5.04^{*}$ & 1 & 518.768 & $5.77^{*}$ \\
\hline Deviations & 1 & 168.929 & 1.87 & 1 & 107.310 & 1.19 \\
\hline Within karyotypes & 1012 & 90.175 & & 1005 & 89.907 & \\
\hline
\end{tabular}

* Significant at 0.05 level.

$(r=-0.068, p<0.05)$ and females $(r=-0.063, p<0.05)$. The same result was obtained correlating the different karyotypic classes with their respective wing length means using the Kendall's nonparametric rank test (table V). Thus, st/st homokaryotypes have, on average, longer wings than heterokaryotypes. When the same statistical test was applied to correlate karyotypic classes with their coefficients of variation, a significant negative correlation was again found (table V), with the variance being smaller in groups with higher degress of heterokaryotypy.

\section{Associations between wing length and genotypes}

The possible associations between wing length and genotypic classes were tested by ANOVA analysis. Significant differences were detected for 2 out of 10 loci in males, with homozygotes for the least common alleles $G l d^{103}$ and $E s t-C^{101}$ having the 
longest wings (tables VI, VII). These results are congruent with the aforementioned fact that individuals with long wings (Class I) had the highest frequency of the Est$C^{101}$ allele. No significant differences were detected in females.

Table V. Kendall's rank correlations between heterokaryotypic classes and their wing length means $(\mathrm{mm})$ and coefficients of variation $(\mathrm{CV})$.

\begin{tabular}{lcccccc}
\hline No of het arms & \multicolumn{4}{c}{ Males } & \multicolumn{3}{c}{ Females } \\
& $\mathrm{N}$ & Mean $\pm S E$ & $C V(\%)$ & $\mathrm{N}$ & Mean $\pm S E$ & $C V(\%)$ \\
\hline 0 & 363 & $1.542 \pm 0.005$ & 6.186 & 214 & $1.722 \pm 0.008$ & 6.797 \\
1 & 398 & $1.543 \pm 0.004$ & 5.185 & 231 & $1.711 \pm 0.007$ & 6.213 \\
2 & 208 & $1.525 \pm 0.006$ & 5.679 & 129 & $1.708 \pm 0.009$ & 5.971 \\
3 & 56 & $1.524 \pm 0.010$ & 4.910 & 37 & $1.696 \pm 0.014$ & 5.038 \\
4 & 5 & $1.514 \pm 0.020$ & 2.954 & 3 & $1.700 \pm 0.035$ & 3.578 \\
Total & 1030 & $\tau=-0.843^{*}$ & $\tau=-0.800^{*}$ & 614 & $\tau=-0.800^{*}$ & $\tau=-1.000^{*}$ \\
\hline
\end{tabular}

${ }^{*}$ Significant at 0.05 level.

Table VI. Mean wing size in $\mathrm{mm}(\bar{Y})$, standard deviation (SD) and sample size $(N)$ for the 3 genotypes involving the 2 more common alleles for the loci $G l d$ and Est-C, in males.

\begin{tabular}{lccccc}
\hline Locus & & $100 / 100$ & $100 /-^{\mathrm{a}}$ & $-/-^{\mathrm{a}}$ & Total \\
\hline \multirow{2}{*}{ Est $\mathrm{C} C$} & $\bar{Y}$ & 1.5376 & 1.5642 & 1.6068 & 1.5394 \\
& $\mathrm{SD}$ & 0.0962 & 0.0903 & 0.0422 & 0.0957 \\
& $N$ & 1060 & 66 & 5 & 1131 \\
\multirow{3}{*}{ Gld } & $\bar{Y}$ & 1.5370 & 1.5419 & 1.5717 & 1.5405 \\
& $S D$ & 0.0952 & 0.0972 & 0.0818 & 0.0955 \\
& $\mathrm{~N}$ & 644 & 368 & 56 & 1068 \\
\hline
\end{tabular}

${ }^{\mathrm{a}}=G l d^{103}$ or Est-C $C^{101}$.

Table VII. Results of the 1-way ANOVA performed to test for wing length differences (in $\mathrm{mm}^{2} \times 10^{4}$ ) among genotypes of $G l d$ and Est-C loci in males.

\begin{tabular}{lrrrrrrr}
\hline Source of variation & \multicolumn{3}{c}{ Gld } & & \multicolumn{3}{c}{ Est-C } \\
\cline { 2 - 8 } & \multicolumn{1}{c}{$d f$} & $M S$ & F & $d f$ & $M S$ & F \\
\hline Among genotypes & 2 & 314.713 & $3.47^{*}$ & 2 & 334.745 & $3.65^{*}$ \\
Linear regression & 1 & 423.707 & $4.67^{*}$ & 1 & 659.806 & $7.20^{* *}$ \\
Deviation from linear regression & 1 & 205.719 & 2.27 & 1 & 9.683 & 0.11 \\
Within genotypes & 1065 & 90.729 & & 1128 & 91.650 & \\
\end{tabular}

* ** Significant at 0.05 and 0.01 levels, respectively. 
There was a positive correlation between individual heterozygosity and wing length which reached significance in males $(r=+0.066, p<0.05)$ but not in females $(r=+0.025, p=0.47)$. The same relationship was found between genotypic classes, sorted by their degree of heterozygosis, when they were correlated with wing length mean using the Kendall's rank test (table VIII). Significant negative correlations between degree of heterozygosity and wing length coefficients of variation for males and females are also presented in the same table. Therefore, individuals and classes with increased levels of enzymatic heterozygosity correspond to longer wings and smaller coefficients of variation.

Table VIII. Kendall's rank correlations between heterozygotic classes and their wing length means ( $\mathrm{mm}$ ) and coefficients of variation (CV).

\begin{tabular}{|c|c|c|c|c|c|c|}
\hline \multirow[t]{2}{*}{ No of het loci } & \multicolumn{3}{|c|}{ Males } & \multicolumn{3}{|c|}{ Females } \\
\hline & $\mathrm{N}$ & $M e a n \pm S E$ & $C V(\%)$ & $N$ & $M e a n \pm S E$ & $C V(\%)$ \\
\hline 0 & 84 & $1.519 \pm 0.013$ & 7.845 & 130 & $1.698 \pm 0.010$ & 6.715 \\
\hline 1 & 240 & $1.546 \pm 0.007$ & 7.026 & 294 & $1.718 \pm 0.007$ & 6.985 \\
\hline 2 & 374 & $1.530 \pm 0.006$ & 7.594 & 242 & $1.716 \pm 0.007$ & 6.357 \\
\hline 3 & 269 & $1.544 \pm 0.006$ & 6.379 & 100 & $1.721 \pm 0.010$ & 5.811 \\
\hline 4 & 120 & $1.552 \pm 0.008$ & 5.654 & 20 & $1.702 \pm 0.022$ & 5.787 \\
\hline 5 & 30 & $1.556 \pm 0.015$ & 5.261 & 2 & $1.568 \pm 0.033$ & 2.991 \\
\hline 6 & 3 & $1.483 \pm 0.072$ & 8.422 & - & - & - \\
\hline 7 & 1 & $1.560 \quad-$ & - & - & - & - \\
\hline Total & 1121 & $\tau=+0.733^{*}$ & $\tau=-0.867^{*}$ & 788 & $\tau=+0.200$ & $\tau=-0.800^{*}$ \\
\hline
\end{tabular}

* Significant at 0.05 level.

The negative correlations for heterokaryotypy and heterozygosis with phenotypic variance were also tested using the non-parametric Wilcoxon's signed-ranks test (Sokal and Rohlf, 1981). In our case, for each analyzed element (chromosome or gene) the total sample was divided in to 2 groups, homozygotes and heterozygotes for that element, and the average coefficient of variation, in order to use male and female data, was calculated for each group. The null hypothesis tested was that heterozygotes have on average the same level of wing length variation as homozygotes. In 19 out of 25 possible tests, heterozygotes had a lower coefficient of variation $(p<0.005)$. Furthermore, the same analysis for each autosome showed that elements in chromosome 3 are primarily responsible for this difference. Ten out of 12 possible tests for chromosome 3 had lower coefficients of variation for heterozygotes $(p<0.005)$, whereas only 6 out of 10 in chromosome 2 showed the same tendency. This result is in accordance with the fact that correlations with wing size were mainly detected with chromosome 3 elements (tables IV, VII).

\section{Association between inversion}

There are 2 possible nonrandom associations between linked cosmopolitan inversions, those between $\operatorname{In}(2 L) t$ and $\operatorname{In}(2 R) N S$ and between $\operatorname{In}(3 L) P$ and $\operatorname{In}(3 R) P$. In 
both cases significant disequilibria, due to an excess of coupling gametes, were found (table IX). Moreover, in a previous survey of this locality (Afonso et al, 1985), similar tendencies were detected, reaching statistical significance for the $3 L-3 R$ pair in spite of the small sample analyzed. It is worth mentioning that whenever significant disequilibria or tendency to disequilibria were detected in worldwide natural pop.ulations of this species, there was invariably an excess of coupling gametes (Knibb et al, 1981).

Only one of 4 possible nonrandom associations between unlinked cosmopolitan inversions was statistically significant (table IX), and again coupling gametes were in excess. Thus the overall tendency of the nonrandom associations found was to favour individuals without inversions or with more than one inversion.

Table IX. Nonrandom associations between inversions and/or allozymes.

\begin{tabular}{llll}
\hline Associations & $\mathrm{R}$ & Associations & $\mathrm{R}$ \\
\hline $2 L-2 R$ & $+0.051^{* *}$ & $3 R-$ Est $-C$ & $-0.028^{*}$ \\
$3 L-3 R$ & $+0.054^{* * *}$ & $3 R-$ Gld & $-0.071^{* * *}$ \\
$2 L-3 L$ & $+0.034^{* *}$ & $3 L-$ Est $C$ & $-0.028^{*}$ \\
$2 L-A d h$ & $+0.335^{* * *}$ & $3 R-E s t-6^{\mathrm{a}}$ & $-0.040^{* *}$ \\
$2 L-\alpha-G p d h$ & $+0.049^{* * *}$ & $3 R-P g m^{\mathrm{a}}$ & $-0.032^{* *}$ \\
$2 R-H k-C$ & $-0.038^{* *}$ & $3 L-H k-C$ & $-0.029^{*}$ \\
$2 L-H k-C$ & $-0.035^{* *}$ & Adh- $\alpha-$ Gpdh & $+0.078^{* * *}$ \\
$2 R-A d h$ & $+0.041^{* * *}$ & Adh - Hk-C & $-0.040^{* * *}$ \\
$2 R-\alpha-G p d h$ & $-0.025^{*}$ & Est $-6-$ Est $-C$ & $+0.047^{* *}$ \\
$3 L-E s t-6$ & $-0.043^{* *}$ & Est $-6-$ Odh & $-0.041^{* *}$ \\
$3 L-P g m$ & $-0.055^{* * *}$ & Pgm - Est $-C$ & $+0.035^{* *}$ \\
\hline
\end{tabular}

*** , ${ }^{* * *}$ Significant at $0.05,0.01$ and 0.001 levels, respectively. ${ }^{a} \operatorname{In}(3 R) C$ and $\operatorname{In}(3 R) P$ rearrangements grouped against standard ones.

\section{Associations between inversions and allozymes}

Of the 16 possible comparisons between linked allozymes and gene arrangements, $13(81 \%)$ were in linkage disequilibrium, but only $1(4 \%)$ out of 24 possible combinations between unlinked inversions and allozymes were in nonrandom association (table IX).

\section{Associations between allozymes}

Of 14 possible combinations between allozyme loci located in the same chromosome, $5(36 \%)$ were in linkage disequilibrium (table IX), 3 of them having an excess and 2 a deficit of coupling gametes. None of the 31 combinations between allozyme loci located in different chromosomes showed significant nonrandom associations. 


\section{DISCUSSION AND CONCLUSION}

In contrast to previous studies, large amounts of linkage disequilibrium have been found in a natural population of $D$ melanogaster. Frequencies of nonrandom associations are stronger between linked than unlinked pairs and also between larger than smaller elements. Thus, frequencies of significant gametic associations between linked and unlinked elements respectively were $100 \%$ and $25 \%$ for chromosome arrangements, $81 \%$ and $4 \%$ for chromosome arrangements and allozymes, and $36 \%$ and $0 \%$ for pairs of allozymes. These values are much higher than those previously reported in natural populations and fairly similar to those found for experimental populations, with the important exception that no significant associations between unlinked allozymes were detected in this study. The relatively large amount of linkage disequilibrium in experimental populations has been mainly attributed to the small size of these populations (Langley et al, 1978; Laurie-Ahlberg and Weir, 1979) although other causes such as selection by varied environments have also been invoked (Birley and Haley, 1987). The first explanation does not seem to be the case for our insular population. Gene arrangement and allozyme frequencies are, temporally, rather stable, and the average number of alleles seems to indicate that the population has not recently suffered important bottlenecks, its population size being comparable to those of continental populations (Cabrera et al, 1982; Afonso et $a l, 1985)$. It is well known that although $D$ melanogaster undergoes seasonal bottlenecks and expansions in population size, the allozyme and chromosomal variation does not seem to be strongly affected (Langley et al, 1977). Nevertheless, the population structure could account for moderate levels of disequilibrium generated by population subdivision due to microspatial heterogeneity (Hoffmann et $a l, 1984)$. The significant departures from $\mathrm{HW}$ equilibrium of several loci and the overall deficiency of mean observed heterozygosity could be explained by this fact. Another possible explanation is that these levels are similar in other natural populations but have not been detected before due to inadequate sample size (Brown, 1975). The temporal stability of the linkage disequilibria found in our population, and their overall consistence with those reported in other worldwide surveys (table $\mathrm{X}$ ), strongly support the action of epistatic selection. Discrepancies in the sign of some nonrandom associations are explainable because they affected loci and inversions genotypically correlated with differences in wing size. The positive sign for all pairs of nonrandom associations between gene arrangements points to frequency dependent selection with a minority advantage (Yamazaki, 1977). On the contrary, the number of negative linkage disequilibria detected in nonrandom associations between inversions and allozymes, $11(79 \%)$ significantly greater $\left(\chi^{2}=4.57,1 \mathrm{df}\right.$, $p<0.05)$ than the positive ones, $3(21 \%)$, suggesting some type of balancing selection (Langley and Crow, 1974) rather than a historical effect (Nei and $\mathrm{Li}, 1980$ ). Finally significant allozyme - allozymes associations are less common and may be a simple consequence of their association with the same inversion, since when these linkages were tested according to Zouros et al (1974) within chromosome arrangements for the 2 significant cases, the associations disappeared $A d h-\alpha-G p d h$ within $2 L(s t)\left(\chi^{2}=1.20,1 \mathrm{df}, \mathrm{NS}\right)$ and Est-6-Pgm within $3 L(s t)$ arrangements $\left(\chi^{2}=2.59\right.$, $1 \mathrm{df}, \mathrm{NS})$. 
Table X. Correlations' sign of nonrandom associations found in natural populations of $D$ melanogaster.

\begin{tabular}{|c|c|c|c|}
\hline \multirow[t]{2}{*}{ Associations } & \multicolumn{2}{|c|}{ Our population } & \multirow[t]{2}{*}{ Others authors ${ }^{\mathrm{c}}$} \\
\hline & $1984^{\mathrm{a}}$ & $1983^{\mathrm{b}}$ & \\
\hline $2 L-2 R$ & + & & $+(1,2)$ \\
\hline $3 L-3 R$ & + & + & $+(2,3)$ \\
\hline $2 L-3 L$ & + & & $+(2)$ \\
\hline $2 L-A d h$ & + & + & $+(1,3,4,5,6,7,8,9,10,11,12)$ \\
\hline $2 L-\alpha-G p d h$ & + & + & $+(1,4,8,10,11,12)$ \\
\hline $2 R-H k-C$ & - & & $-(9)$ \\
\hline $2 L-H k-C$ & - & & $(1,3,9,11)$ \\
\hline $2 R-A d h$ & + & & $+(1,6,8)$ \\
\hline $2 R-\alpha-G p d h$ & - & & $(1,3,4,8,9,10,11,12)$ \\
\hline $3 L-E s t-6$ & - & - & $-(3,4)$ \\
\hline $3 L-P g m$ & - & & $-(4)$ \\
\hline $3 R-$ Est-C & - & & $-(4,5)$ \\
\hline $3 R-G l d$ & - & ( ) & ()$^{1}$ \\
\hline $3 L-E s t-C$ & - & & $+(11)$ \\
\hline $3 R-E s t-6$ & - & & $-(4)$ \\
\hline $3 R-P g m$ & - & & $(3,4,11)$ \\
\hline $3 L-H k-C$ & - & & $(3,11)$ \\
\hline$A d h-\alpha-G p d h$ & + & + & $+(1)$ \\
\hline$A d h-H k-C$ & - & & $(1,3,6,9,11,13)$ \\
\hline Est-6 - Est-C & + & & $(4,5,11)$ \\
\hline Est-6 - Odh & - & ( ) & $(3,4,5,11)$ \\
\hline Pgm - Est-C & + & & $(4,11,13)$ \\
\hline $3 R-O d h$ & & ( ) & $+(4,5)$ \\
\hline$\alpha-G p d h-H k-C$ & & & $+(13)$ \\
\hline$P g m-O d h$ & & () & $-(11)$ \\
\hline
\end{tabular}

,+- Excess of coupling and repulsion gametes, respectively as in Langley et al (1974); ( ) absence of sample; ${ }^{\mathrm{a}}$ this study ; ${ }^{\mathrm{b}}$ Afonso et al (1985); ${ }^{\mathrm{c}}$ (1) Yamaguchi et al (1980); (2) Knibb et al (1981); (3) Langley et al (1977) ; (4) Langley et al (1974); (5) Kojima et al (1970); (6) Mukai et al (1971); (7) Voelker et al (1977); (8) Mukai et al (1974); (9) Mukai and Voelker (1977); (10) Watanabe and Watanabe $(1977) ;(11)$ Yamazaki et al (1984); (12) Knibb (1983); (13) Marinkovic et al (1987).

The significant correlations found between karyotypes and genotypes with the quantitative trait suggest a measurable genetic component within a natural population in the phenotypic variation of a character with low heritability (Prout, 1958; Coyne and Beecham, 1987). Although both autosomes seem to influence wing length, the effect of chromosome 3 was stronger.

Although there are some negative results (Handford, 1980; Pierce and Mitton, 1982) several reports on the relationship between genetic and karyotypic heterozygosity and morphological variation seem to indicate that, as in experimental populations, a negative correlation between genetic heterozygosity and morphological variance also exists in natural populations of some animals and plants (Mitton and 
Grant, 1984; Zouros and Foltz, 1987). Our results in $D$ melanogaster agree with this supposition as both in individual or genotypic classes, heterozygotes and heterokaryotypes showed significantly less morphological variance than homozygotes and homokaryotypes respectively. Robertson and Reeve (1952a) also reported the existence of this negative correlation in the same species. Their explanation for this phenomenon was that more heterozygous individuals will carry a greater diversity of alleles that endows them with a greater biochemical versatility in development. Nevertheless, other authors (Chakraborty, 1987) claimed that these negative correlations between heterozygosity and phenotypic variance can be explained by additive allelic effects without implying heterosis, overdominance or associative overdominance. In fact, when following the methods of Boerwinkle and Sing (1986) and Ruiz et al (1991) to estimate the underlying mechanism that might cause these associations in our data (table XI) practically the totality of the variance among classes $\left(\sigma_{k}^{2}\right)$ can be explained by additive effects $\left(\sigma_{a}^{2}\right)$.

Table XI. Estimated contribution of the factors, which showed significant associations with wing length, to the phenotypic variance of this trait (in $\mathrm{mm}^{2} \times 10^{4}$ ).

Components of phenotypic variance

\begin{tabular}{llccccc} 
& & $\sigma_{\mathrm{a}}^{2}$ & $\sigma_{\mathrm{d}}^{2}$ & $\sigma_{\mathrm{k}}^{2}$ & $\sigma^{2}$ & $\sigma_{\text {total }}^{2}$ \\
\hline \multirow{4}{*}{ Males } & $3 L$ & 0.359 & 0.078 & 0.437 & 90.174 & 90.611 \\
& $3 R$ & 0.427 & 0.017 & 0.444 & 89.907 & 90.351 \\
& Gld & 0.313 & 0.108 & 0.421 & 90.729 & 91.150 \\
& Est $C$ & 0.503 & -0.073 & 0.430 & 91.650 & 92.080 \\
Females & $3 R$ & 0.378 & -0.085 & 0.293 & 121.719 & 122.012 \\
& Est $C$ & 0.282 & 0.011 & 0.293 & 123.470 & 123.763 \\
\hline
\end{tabular}

$\sigma_{a}^{2}$ : Variance due to the additive effects of the chromosome arrangements or allozymic alleles; $\sigma_{d}^{2}$ : variance due to the deviations from additivity; $\sigma_{k}^{2}$ : variance among groups; $\sigma^{2}$ : variance within groups.

An apparent contradiction seems to exist in the sign of the correlations found between heterokaryotypy and heterozygosis with averages of wing length at individual or genotypic class levels. Wing length averages are positively correlated with homokaryotypy but negatively with homozygosis, but a significant positive correlation also exists between heterozygosis and heterokaryotypy both in males $(r=+0.968, p<0.01)$ and females $(r=+0.988, p<0.01)$. The explanation is that within each heterokaryotypic class, the largest individuals are the most heterozygous.

As there are gametic associations between gene arrangements and enzymatic loci, both correlated with differences in wing length, we tested whether a genuine correlation exists between the Gld and Est-C loci and wing length within the homokaryotypic individuals for the $3 R$ standard arrangement. It can be seen in table XII that a significant association among genotypes and wing length exists independently of the association of the allozymes and gene arrangements. 
Table XII. Results (in $\mathrm{mm}^{2} \times 10^{4}$ ) of the 1-way ANOVA carried out to test for wing length differences among genotypes of Est-C and Gld loci within the standard arrangement for the $3 R$ chromosomic arm.

\begin{tabular}{|c|c|c|c|c|c|c|}
\hline \multirow[t]{2}{*}{ Source of variation } & \multicolumn{3}{|c|}{ Est-C } & \multicolumn{3}{|c|}{ Gld } \\
\hline & $d f$ & $M S$ & $F$ & $d f$ & $M S$ & $\mathbf{F}$ \\
\hline Among genotypes & 2 & 253.444 & $2.77^{\mathrm{a}}$ & 2 & 234.673 & $2.56^{\mathrm{a}}$ \\
\hline Regression & 1 & 479.293 & $5.24^{*}$ & 1 & 384.566 & $4.19^{*}$ \\
\hline Deviations & 1 & 27.596 & 0.30 & 1 & 84.779 & 0.92 \\
\hline Within genotypes & 731 & 91.398 & & 693 & 91.830 & \\
\hline
\end{tabular}

${ }^{*}$ Significant at 0.05 level; ${ }^{\mathrm{a}} p=0.08$.

The interaction found among wing length, chromosome and genic variation fits in very well with the natural population patterns. Northern marginal populations have longer wings, reduced heterokaryotypy and similar heterozygosis compared to central and southern populations. However, there is a discrepancy with experiments of artificial directional selection. Selection for long wings favours heterozygous combinations for chromosomal arrangements, whereas selection for short wings generally fixed specific chromosomal arrangements in homozygous combination (Prevosti, 1967). It seems that experimental selection goes further than the seasonal and latitudinal natural selection. Since long size is well correlated with high levels of heterozygosity (Robertson and Reeve, 1952b) the best way to delay homozygosity due to inbreeding is the maintenance of different gene arrangements that physically preserve heterozygosity. On the other hand, selection for short wings in this species favours homokaryotypy for non-standard gene arrangements which are more common in southern populations (Aguadé and Serra, 1980; Serra and Oller, 1984).

The strong associations found here among different levels of variation seem to possess a potentially high adaptive value, as was manifested when we subdivided the sample by differences in wing size, resembling the clinal variation existent for this quantitative character in natural populations of the species. Subdivision changed the level of heterokaryotypy and promoted differences in the frequencies of some allozymes linked to gene arrangements as in nature.

\section{REFERENCES}

Afonso JM, Hernández M, Padrón G, González AM (1985) Gametic non random associations in northwest African populations of Drosophila melanogaster. Genetica $67,3-11$

Aguadé M, Serra L (1980) Spanish cellar populations of $D$ melanogaster. I. Study of variability at three different levels: quantitative, chromosomal and molecular Genetika 12, 111-120

Anderson PR, Oakeshott JG (1984) Parallel geographical patterns of allozyme variation in two sibling Drosophila species. Nature (Lond) 308, 729-731 
Ashburner M, Lemeunier F (1976) Relationships within the melanogaster species subgroup of the genus Drosophila (Sophophora). I. Inversion polymorphisms in Drosophila melanogaster and Drosophila simulans. Proc $R$ Soc Lond B 193, 137-157 Birley AJ, Haley CS (1987) The genetical response to natural selection by varied environments. IV. Gametic disequilibrium in spatially varied environments. Genetics 115, 295-303

Boerwinkle E, Sing CF (1986) Bias of the contribution of single-locus effects to the variance of a quantitative trait. Am J Hum Genet 39, 137-144

Brown AHD (1975) Sample sizes required to detect linkage disequilibrium between two or three loci. Theor Pop Biol Biol 8, 184-201

Cabrera VM, González AM, Larruga JM, Gullón A (1982) Electrophoretic variability in natural populations of Drosophila melanogaster and Drosophila simulans. Genetica 59, 191-201

Cavener DR (1980) Genetics of male-specific glucose oxidase and the identification or other unusual hexose enzymes in Drosophila melanogaster. Biochem Genet 18, 929-938

Chakarborty R (1987) Biochemical heterozygosity and phenotypic variability of polygenic traits. Heredity $59,19-28$

Choudhary M, Singh RH (1987) A comprehensive study of genic variation in natural populations of Drosophila melanogaster. III. Variation in genetic structure and their causes between Drosophila simulans. Genetics 117, 697-710

Cockerham CC, Weir BS (1977) Digenic descent measures for finite populations. Genet Res 30, 121-147

Coyne JA, Beecham B (1987) Heritability of two morphological characters within and among natural populations of Drosophila melanogaster. Genetics 117, 727-737 Cohan FM, Graf JD (1985) Latitudinal cline in Drosophila melanogaster for knockdown resistance to ethanol fumes and for rates of response to selection for further resistance. Evolution 39, 278-293

Crow JF (1987) Population genetics history: a personal view. Annu Rev Genet 21, 1-22

David JR, Bocquet C (1975) Similarities and differences in latitudinal adaptation of two Drosophila sibling species. Nature 257, 588-590

David J, Bocquet C, Scheemaeker-Louis M (1977) Genetic latitudinal adaptation of Drosophila melanogaster: new discriminative biometrical traits between European and equatorial African populations. Genet Res 30, 247-255

González AM, Cabrera VM, Larruga JM, Gullón A (1982) Genetic distance in the sibling species Drosophila melanogaster, Drosophila simulans and Drosophila mauritiana. Evolution 36, 517-522

Handford P (1980) Heterozygosity at enzyme loci and morphological variation. Nature 286, 261-262

Hoffmann AA, Nielsen KM, Parsons PA (1984) Spatial variation of biochemical and ecological phenotypes in Drosophila: electrophoretic and quantitative variation. Dev Genet 4, 439-450

Inoue Y, Watanabe TK (1979) Inversion polymorphisms in Japanese natural populations of Drosophila melanogaster. Jpn J Genet 54, 69-82 
Inoue Y, Tobari YN, Tsuno K, Watanabe TK (1984) Association of chromosome and enzyme polymorphisms in natural and cage populations of Drosophila melanogaster. Genetics 106, 267-277

Kimura M (1983) The Neutral Theory of Molecular Evolution. Cambridge Univ Press, Cambridge

Knibb WR (1982) Chromosome inversion polymorphisms in Drosophila melanogaster. II. Geographic clines and climatic associations in Australasia, North America and Asia. Genetica 58, 213-221

Knibb WR (1983) Chromosome inversion polymorphism in Drosophila melanogaster. III. Gametic disequilibria and the contributions of inversion clines to the Adh and Gpdh clines in Australasia. Genetica 61, 139-146

Knibb WR, Oakeshott JG, Gibson JB (1981) Chromosome inversion polymorphisms in Drosophila melanogaster. I. Latitudinal clines and associations between inversions in Australasian populations. Genetics 98, 833-847

Kojima K, Gillespie J, Tobari YN (1970) A profile of Drosophila species enzymes assayed by electrophoresis. I. Number of alleles, heterozygosities and linkage disequilibrium in glucose-metabolizing systems and some other enzymes. Biochem Genet 4, 627-637

Kusakabe S, Mukai $\mathrm{T}$ (1984) The genetic structure of natural populations of Drosophila melanogaster. XVIII. Clinal and uniform genetic variation over populations. Genetics 108, 617-632

Langley CH, Crow JF (1974) The direction of linkage disequilibrium. Genetics 78, 937-941

Langley CH, Tobari YN, Kojima K (1974) Linkage disequilibrium in natural populations of Drosophila melanogaster. Genetics 78, 921-936

Langley CH, Ito K, Voelker RA (1977) Linkage disequilibrium in natural populations of Drosophila melanogaster. Seasonal variation. Genetics 86, 447-454

Langley CH, Smith DB, Johnson FM (1978) Analysis of linkage disequilibria between allozyme loci in natural populations of Drosophila melanogaster. Genet Res 32, 215-230

Laurie-Ahlberg CC, Weir BS (1979) Allozymic variation and linkage disequilibrium in some populations of Drosophila melanogaster. Genetics 92, 1295-1314

Lefevre G Jr (1976) A photographic representation and interpretation of the polytene chromosomes of Drosophila melanogaster salivary glands. In: The Genetics and Biology of Drosophila (Ashburner M, Novitski E, eds) Academic Press, London, vol 1a, 31-66

Lewontin RC (1974) The Genetic Basis of Evolutionary Change. Columbia Univ Press, New York

Lindslsey DL, Grell EH (1967) Genetic Variations of Drosophila melanogaster. Carnegie Inst, Washington, Publ No 627

Marinkovic D, Tucic N, Moya A, Ayala FJ (1987) Genetic diversity and linkage disequilibrium in Drosophila melanogaster with different rates of development. Genetics 117, 513-520

Mayer PJ, Baker GT (1983) Delayed dissemination by low temperature exposure in two strains of $D$ melanogaster. Drosophila Inform Serv 59,84

Mettler LE, Voelker RA, Mukai T (1977) Inversion clines in populations of Drosophila melanogaster. Genetics 87, 169-176 
Mitton JB, Grant MC (1984) Associations among protein heterozygosity, growth rate, and developmental homeostasis. Annu Rev Ecol Syst 15, 479-499

Mukai T, Voelker RA (1977) The genetic structure of natural populations of Drosophila melanogaster. XIII. Further studies on linkage disequilibrium. Genetics $86,175-185$

Mukai T, Mettler LE, Chigusa SI (1971) Linkage disequilibrium in a local population of Drosophila melanogaster. Proc Natl Acad Sci USA 68, 1065-1069

Mukai T, Watanabe TK, Yamaguchi O (1974) The genetic structure of natural populations of Drosophila melanogaster. XII. Linkage disequilibrium in a large local population. Genetics 77, 771-793

Nei $M$ (1971) Fertility excess necessary for gene substitution in regulated populations. Genetics 68, 169-184

Nei M (1975) Molecular Population Genetics and Evolution. North Holland, Amsterdam

Nei M, Li W-H (1980) Non random association between electromorphs and inversion chromosomes in finite populations. Genet Res 35, 65-83

Nie NH, Hull CH, Jenkins JG, Steinbrenner K, Bent DH (1975) Statistical Package for the Social Sciences. McGraw-Hill Book Co, NY

Pierce BA, Mitton JB (1982) Allozyme heterozygosity and growth in tiger salamander, Ambyostoma tigrinum. J Hered 73, 250-253

Prevosti A (1967) Inversion heterozygosity and selection for wing length in Drosophila subobscura. Genet Res 10, 81-94

Prout T (1958) A possible difference in genetic variance between wild and laboratory populations. Drosophila Inform Serv 32, 148-149

Reeve ECR, Robertson FW (1953) Studies in quantitative inheritance. II. Analysis of a strain of Drosophila melanogaster selected for long wings. J Genet 51, 276-316 Robertson FW, Reeve CR (1952a) Heterozygosity, environmental variation and heterosis. Nature (Lond) 170, 286

Robertson FW, Reeve CH (1952b) Studies in quantitative inheritance. I. The effects of selection of wing and thorax length in $D$ melanogaster. $J$ Genet 50, 414-448

Ruiz A, Santos M, Barbadilla A, Quezada-Diaz JE, Hasson E, Fontdevila A (1991) Genetic variance for body size in a natural population of Drosophila buzzatii. Genetics 128, 739-750

Schaffer HE, Johnson FM (1974) Isozyme allelic frequencies related to selection and gene-flow hypotheses. Genetics $77,163-168$

Serra L, Oller JM (1984) Analysis of allozymic and quantitative variation produced by artificial selection in Drosophila melanogaster. Genetica 63, 39-47

Singh RS, Hickey DA, David J (1982) Genetic differentiation between geographically distant populations of Drosophila melanogaster. Genetics 101, 235-256

Singh RS, Rhomberg LR (1987) A comprehensive study of genic variation in natural populations of Drosophila melanogaster. II. Estimates of heterozygosity and patterns of geographic differentiation. Genetics 117, 255-272

Sokal RR, Rohlf FJ (1981) Biometry. WH Freeman and Co, NY, 2nd edn Stalker HD (1976) Chromosome studies in wild populations of $D$ melanogaster. Genetics 82, 323-347 
Stalker HD (1980) Chromosome studies in wild populations of Drosophila melanogaster. II. Relationship of inversion frequencies to latitude, season, wing-loading and flight activity. Genetics $95,211-223$

Tantawy AO, Mallah GS (1961) Studies on natural population of Drosophila. I. Heat resistance and geographical variation in Drosophila melanogaster and D simulans. Evolution 15, 1-14

Voelker RA, Mukai T, Johnson FM (1977) Genetic variation in populations of Drosophila melanogaster from the western United States. Genetica 47, 143-148

Voelker RA, Cockerham CC, Johnson FM, Schaffer HE, Mukai T, Mettler LE (1978) Inversions fail to account for allozyme clines. Genetics 88, 515-527 